\title{
Can We augment the US Trauma Fellow's Operative Training? The PTS Fellowship: A US Surgical Critical Care Fellow's Experience in Colombia
}

\author{
${ }^{1}$ Gregory Lance Peck, ${ }^{2}$ Ferrada Paula, ${ }^{3}$ Hanna Joseph, ${ }^{4}$ Ricardo Ferrada, ${ }^{5}$ Dente Christopher, ${ }^{6}$ Carlos Ordonez \\ ${ }^{7}$ Michael Aboutanos, ${ }^{8}$ Vicente Gracias
}

\begin{abstract}
Objective: To send an American fellow surgeon to a Panamerican country and quantify operative skills acquisition.

Materials and methods: A second year surgical critical care fellow from a Level One Urban Trauma Center was sent to Cali, Colombia from April 1 to 21, 2013. The operative experience was evaluated. Total cases, first time cases, and first time procedures, defined as technical portions within trauma cases, were recorded.
\end{abstract}

Results: In 20 operative days, 172 total cases were performed in the following categories: burn 112, trauma 19, emergent general 16 , elective general 14 , plastics 8 , and laparoscopic bariatric 3 . First exposure operations included $46 / 112$ burn cases, 8/8 trauma/burn reconstructive cases, 1/16 emergent general cases, 11/14 elective general cases, and 3/3 laparoscopic bariatric cases. Of the 19 total trauma operations (not including 2 amputations), 3 left anterolateral thoracotomies, 2 clamshell thoracotomies, 1 diagnostic laparoscopy, 1 open pericardial window, 10 exploratory laparotomies and 2 relaparotomies were performed. The 19 trauma operations consisted of 26 (not including the 2 amputations) procedures. Twenty-three percent were first time performed trauma procedures $(6 / 26$, not including amputations).

Nearly 9 (8.6) operations were performed per day. In five 12-hour shifts of trauma call, 19 operations were performed within 60 hours. One trauma operative case was performed for every 3.15 hours worked.

\footnotetext{
${ }^{1-3}$ Assistant Professor, ${ }^{4,6-8}$ Professor, ${ }^{5}$ Associate Professor

${ }^{1,3}$ Department of Acute Care Surgery, Rutgers UniversityRobert Wood Johnson Medical School, Medical Center, New Jersey, USA

${ }^{2,7}$ Department of Surgery, Virginia Commonwealth University Richmond, VA, USA

${ }^{4}$ Department of Surgery, Universidad del Valle, Cali, Colombia

${ }^{5}$ Department of Surgery, Emory University, GA, USA

${ }^{6}$ Department of Surgery, Clinica De Amiga, Cali, Colombia

${ }^{8}$ Department of Surgery, Rutgers University-Robert Wood Johnson Medical School, New Jersey, USA
}

Corresponding Author: Gregory Lance Peck, Assistant Professor, Department of Acute Care Surgery, Rutgers University-Robert Wood Johnson Medical School, New Jersey USA, Phone: 7322357766, e-mail: peckgr@rutgers.rwjms.edu
Conclusion: In the current era of American trauma training in which penetrating trauma and total number of operative cases is concentrated to specific centers in the United States, additional methods in education and experience should be sought for the American trauma fellow. This is the first reported international trauma fellow rotation in Cali, Colombia, with an operative experience very different than standard and current opportunities. Our experience serves as a potential template for future endeavors in surgical education.

Keywords: Panamerican trauma fellowship, International trauma fellowship, Trauma rotation.

How to cite this article: Peck GL, Paula F, Joseph H, Ferrada R, Christopher D, Ordonez C, Aboutanos M, Gracias V. Can We augment the US Trauma Fellow's Operative Training? The PTS Fellowship: A US Surgical Critical Care Fellow's Experience in Colombia. Panam J Trauma Crit Care Emerg Surg 2014;3(1):1-7.

Source of support: Nil

Conflict of interest: None

\section{ABSTRACTO}

Objetivo: Para enviar un Fellow American Surgeon a un país Panamericana y cuantificar la adquisición de habilidades operativas.

Métodos: Un segundo año Surgical Critical Care Compañeros de un Urbano Centro de Trauma de Nivel Uno fue enviado a Cali Colombia desde 1 a 21 abril 2013 La experiencia operativa se evaluó. Total de casos, casos por primera vez, y los procedimientos por primera vez, define como partes técnicas en casos de trauma, se registraron.

Resultados: En 20 días operativos, 172 casos en total se llevaron a cabo en las siguientes categorías; Quemar 112, Trauma 19, Emergent general 16, General Electivo 14, Plásticos 8 y laparoscópica bariátrica 3. Operaciones de la Primera exposición incluyen 46/112 casos de quemaduras, 8/8 Trauma/quemar casos reconstructivos, $1 / 16$ casos Emergent Generales, 11/14 casos electivos generales, y $3 / 3$ casos laparoscópica bariátrica. De las 19 operaciones totales de trauma (no incluyendo 2 amputaciones), 3 Izquierda anterolaterales toracotomías, 2 Clamshell toracotomías, 1 laparoscopia de diagnóstico, 1 Abra pericárdico Ventana, se realizaron 10 laparotomías exploradoras y 2 re-laparotomías. Las 19 operaciones de trauma consistieron en 26 (no incluyendo las amputaciones 2 ) procedimientos. $23 \%$ fueron procedimientos primera vez realizadas trauma $(6 / 26$, sin incluir las amputaciones).

Casi 9 (8.6) las operaciones se realizaron por día. En cinco, turnos de doce horas de llamada trauma, se realizaron 19 
operaciones en 60 horas. Caso operativo Uno trauma se realizó por cada 3,15 horas trabajadas.

Conclusión: En la era actual de la formación trauma estadounidense en la que el trauma penetrante y el número total de casos quirúrgicos se concentra a centros específicos en los Estados Unidos, los métodos adicionales en la educación y la experiencia debe buscarse la American Trauma Fellow. Este es el primer informe de compañero de trauma rotación internacional en Cali Colombia, con una experiencia operativa muy diferente a la estándar y oportunidades actuales. Nuestra experiencia sirve como plantilla potencial para futuros esfuerzos en la educación quirúrgica.

Palabras claves: Communion trauma panaerica, Communion operative internacional, Rotacion trauma.

\section{INTRODUCTION}

In the last three decades, as the volume of operative trauma has declined in large part to decreasing crime rates in large urban centers in the United States, ${ }^{1}$ as well as the increasing prevalence of appropriately selected nonoperative management of injuries, the number of trauma surgeons practicing an acceptable range of operative procedures has decreased dramatically. ${ }^{2}$ As of 2008 , only $18 \%$ of 169 level one trauma centers surveyed in the United States reported that their surgeons 'perform the full complement of thoracic, vascular, and abdominal cases' deemed as necessary to maintain an acceptable level of expertise. ${ }^{2}$ In reaction to the declining operative load for trauma surgeons, many centers have embraced a model in which emergency general surgery is increasingly being managed by traumatologists to maintain their operative skills. ${ }^{3,4}$ Given this observed shift in operative exposure for the trauma service, it is reasonable to infer that the current training of trauma fellows is quite variable. This training appears to be dependent on supervising staff experience, location of the training program (urban $v s$ rural), prior operative exposure as a general surgery resident, ${ }^{5}$ changes in training practices engendered by increasing loss of resident autonomy, ${ }^{6}$ the mandatory decrease in resident work hours, ${ }^{7}$ and perhaps other variables which remain unrecognized. As this evolution has occurred, there is a paucity of data describing what this means qualitatively for the trauma fellow's education. Moreover, little has been written about, or any consensus been reached, on the minimum operative experience required to certify that a trauma fellow has been adequately trained. Given these issues, can we safely assume that all trauma fellows are being adequately trained? Hoyt et al in 2008 point out that trainees themselves question the integrity of the training system with 'concerns of maintenance of adequate operative experience'. ${ }^{8}$

Leadership within the trauma community has recognized these concerns over the last two decades and spearheaded the development of parallel programs to enhance training.
Furthermore, US trauma fellows have expressed significant concerns about their training and preparedness to enter the workforce. Chiu et al qualified this sentiment in a recent study of trainee attitudes toward their education. ${ }^{9}$ For this reason, pioneers, such as Lenworth Jacobs and organizations, such as the committee on trauma initiated and lead efforts for simulation curriculum development. Courses, such as Advanced Trauma Operative Management (ATOM) and Advanced Surgical Skills for Exposure in Trauma (ASSET), were supported and disseminated through the American College of Surgeons to improve trainees experience and comfort with operative exposure and techniques considered to be essential in the management of advanced trauma care. And, certainly not an exhausting list, but other programs, such as Definitive Surgical Trauma Care (DSRC), were developed under the auspices of the International Association for Trauma Surgery and Intensive Care (IATSIC). The Panamerican Trauma Society conducts a 1 to 2 days course on surgical skills in the animal and cadaveric laboratory. Certainly, the concern and effort is real. More recently, the acute care surgery specialty model was developed in recognition of the benefit of incorporating emergency general surgery into the trauma surgeon's practice to maintain operative skills. ${ }^{10}$

At the EAST Panamerican Trauma Subcommittee meeting 2011, many leaders presented their international trauma endeavors. We considered that a current disparity in operative experience for the American trained trauma fellow existed, and sought out to build a reproducible, formal international partnership that would augment the operative experience of the American fellow. No formal experience like this existed. Conceptually, it was similar to ideas in the past, like 'Advancing Essential Trauma Care through the partner organizations: IATSIC, ISS-SIC and WHO'. However, it would be unique in its primary educational focus ... the American trauma fellow in international travel.

Herein, we describe our efforts to augment the education of US surgical fellow trainees by establishing an international trauma fellowship. Would our fellows complete 'index' procedures using the frameworks previously developed in ATOM, ASSET and DSTC. Recognizing that developing nations continue to experience significant rates of violent crime necessitating emergent trauma operative intervention, we present a fellowship educational program with our international colleagues in Cali, Colombia. This experience builds upon the fundamentals learned through traditional experiential training models, but in real time. We hypothesize that the Panamerican trauma fellowship provides a concentrated, timely exposure to essential index trauma operative procedures in an under served urban environment that is unparalleled by most current learning environments. 


\section{MATERIALS AND METHODS}

A prospectively accrued operative log was maintained by a second year, PGY-7 American trauma fellow sent to Colombia from an American level one urban trauma center. The subject surgeon participated in a 20-day operative and surgical critical care experience from April 1st to April 21st 2013. The experience occurred at four different hospitals in Cali, Colombia, including public, private, community and university settings; Medico Imbanaco, Clinica de Amiga, Clinica Neustra Senora de Los Remedios, and Universidad del Valle, respectively. The number, category, and type of operation were carefully recorded in subjects case log. The experiences were recorded and emphasis placed on first exposure operations and first exposure procedures, defined as specific components of the whole trauma operation, i.e. technical maneuvers of the operation. An example is 'medial visceral rotation performance' within a 'laparotomy case'.

\section{RESULTS}

During the study period, 172 operations were performed in the following categories: burn surgery $(n=112)$, trauma ( $\mathrm{n}=19, \mathrm{n}=21$ if 2 amputations included), trauma/burn reconstructive surgery $(\mathrm{n}=8)$, emergent general surgery $(n=16)$, elective general surgery $(n=14)$, and laparoscopic bariatric surgery ( $n=3)$ (Tables 1 to 6$)$.

Several operations were first exposure for the subject surgeon. These included $46 / 112$ burn cases, $8 / 8$ trauma/burn reconstructive cases, $1 / 16$ emergent general surgery cases, $11 / 14$ elective general surgery cases, and 3/3 laparoscopic bariatric cases. Three-port laparoscopic cholecystectomy and open posterior preperitoneal inguinal hernia repair in the elective general surgery category are examples of first time operations for the subject surgeon (see Tables 1 to 5).

Of the 19 total trauma operations (not including 2 amputations), 3 left anterolateral thoracotomies, 2 clamshell thoracotomies, 1 diagnostic laparoscopy, 1 open pericardial window, 10 exploratory laparotomies and 2 relaparotomies were performed. The 19 operations consisted of 26 (not including the 2 amputations) procedures (Tables 6 and 7). The subject fellow surgeon had $23 \%$ first time procedures (6/26, not including amputations). These included aortic arch repair and left atrial repair both via clamshell thoracotomy, left ventricular repair via left anterolateral thoracotomy, abdominal aortic repair and trauma hysterectomy both via laparotomy, and transdiaphragmatic transabdominal pericardial window via laparoscopy (see Tables 6 and 7).

The 20-day operative rotation afforded the subject fellow 112 burn cases. Nearly half of those cases 50/122 were skin grafts, while 43/50 were performed with Meek micrografting (see Table 2).

The subject fellow conducted 8.6 operations per day on average. In five 12-hour shifts of trauma call, 19 operations were performed within 60 hours. Therefore, on average, one trauma operative case was performed for every 3.15 hours worked.

\section{DISCUSSION}

In the current era of American trauma fellowship training in which penetrating and total number of operative caseload is declining and exposure more concentrated to specific centers in the United States, additional methods in operative education and experience need be made available. Enhanced simulation training has offered a fraction of the solution to skill set acquisition for advanced trauma surgery training. We demonstrate a promising opportunity to enhance US trauma surgery training. Our study of an American fellow's experience in Cali, Colombia, is the first attempt to describe an extensive operative caseload available to United States fellowship trainees. This experience is the first formalized International Fellowship via the Panamerican Trauma Society.

This type of international fellowship offers several advantages. There is the opportunity for enhanced exposure to many operations that educators consider essential cases in trauma operative care, i.e. cardiac exposure, resuscitative anterolateral thoracotomy, advanced retroperitoneal exposure with right and left visceral rotations, isolation of vascular injuries and others. Currently, there is no definition, standard, or minimal case log requirement to suggest how many of these index cases provide proficiency.

The international fellowship provided the subject fellow surgeon first time exposure to many complex trauma operations and completion of particular procedures vital for training. The procedures are categorized under the main operation. If during the operations, the procedures were performed for the first time, it was recorded as such.

Table 1: Total categorical operative experience

\begin{tabular}{ll}
\hline All categories & $N$ \\
\hline Burn & 112 \\
Trauma (21, if amputations) & $19(21)$ \\
Emergent general surgery & 16 \\
Elective general surgery & 14 \\
Plastics (reconstructive) & 18 \\
Laparoscopic bariatric & 3 \\
\hline Total & 172 \\
\hline
\end{tabular}

Table 2: Burn operative experience

\begin{tabular}{llll}
\hline Burn category & Total & Group & Individual \\
\hline Escharotomy & & 22 & \\
Debridement & & 40 & \\
STSG & 50 & \\
$\quad$ Meek micrografting & & & 43 \\
$\quad$ Sheet grafts & & & 7 \\
\hline Burn total & 112 & & \\
\hline
\end{tabular}


Table 3: Elective general surgery operative experience

\begin{tabular}{|c|c|c|c|}
\hline $\begin{array}{l}\text { Elective general } \\
\text { surgery category }\end{array}$ & Total & Group & Individual \\
\hline Hernia & & 9 & \\
\hline Femoral & & & 1 \\
\hline $\begin{array}{l}\text { Inguinal (open posterior } \\
\text { preperitoneal) }\end{array}$ & & & 8 \\
\hline UHR during cholecystectomy & & & 4 \\
\hline Lap cholecystectomy & & 5 & \\
\hline 3 ports & & & 3 \\
\hline 4 ports & & & 2 \\
\hline Elective general surgery total & 14 & & \\
\hline
\end{tabular}

Table 4: Emergent general surgery operative experience

\begin{tabular}{|c|c|c|c|}
\hline Emergent surgery category & Total & Group & Individual \\
\hline Lap cholecystectomy & & 7 & \\
\hline 3 ports & & & 1 \\
\hline 4 ports & & & 6 \\
\hline Appendectomy & & 4 & \\
\hline Open & & & 2 \\
\hline Laparoscopic & & & 2 \\
\hline Hernia & & 4 & \\
\hline $\begin{array}{l}\text { Incarcerated inguinal (inguinal } \\
\text { approach) }\end{array}$ & & & 2 \\
\hline Incarcerated—ventral SB & & & 1 \\
\hline Incarcerated-ventral colon & & & 1 \\
\hline Laparotomy & & 1 & \\
\hline Colon resection & & & 1 \\
\hline
\end{tabular}

Table 5: Reconstructive operative experience

\begin{tabular}{|c|c|c|c|}
\hline Reconstructive category & Total & Group & Individual \\
\hline Rotational flap & & 5 & \\
\hline Pectoralis & & & 1 \\
\hline Occipital & & & 2 \\
\hline Ulnar & & & 1 \\
\hline Soleus & & & 1 \\
\hline Pedicle flap & & 3 & \\
\hline Groin & & & 3 \\
\hline
\end{tabular}

Reconstructive total 8

It is important to note that when interpreting procedure first time performance rate in our results, our experience only reflects a single fellow's experience in Colombia. The single experience and first time procedure rates are considered only in the context of the fellows past experience. Trauma operative fellowship experience in the United States is anecdotally variable, and therefore, first time procedure percentages will be widely variable as well. Given the subject fellows Pre-international fellowship training experience in a busy level one urban center with large numbers and percentage of penetrating trauma, the first time procedure percentage would perhaps under represent the potential operative opportunity for a fellow with different background operative experience. Our quantitative report is therefore limited due to
Table 6: Trauma operative experience

\begin{tabular}{|c|c|c|c|}
\hline Trauma category & Total & Group & Individual \\
\hline Left anterolateral thoracotomy & & 3 & \\
\hline Right cardiac repair & & & 1 \\
\hline Left cardiac repair & & & 1 \\
\hline Pleural repair & & & 3 \\
\hline Clamshell thoracotomy & & 2 & \\
\hline Aortic arch repair & & & 1 \\
\hline Left cardiac repair & & & 1 \\
\hline Pleural repair & & & 3 \\
\hline Diagnostic laparoscopy & & 1 & \\
\hline Transabd. transdiaph window & & & 1 \\
\hline Lap diaphragmatic repair & & & 1 \\
\hline Open pericardial window & & 1 & 1 \\
\hline Laparotomy & & 10 & \\
\hline Abdominal aortic repair & & & 1 \\
\hline Iliac vein repair & & & 1 \\
\hline Nephrectomy & & & 1 \\
\hline Colectomy, enterectomy & & & 1 \\
\hline Hysterectomy/abortion & & & 1 \\
\hline Splenectomy & & & 1 \\
\hline Distal pancreatectomy & & & 1 \\
\hline Nontherapeutic & & & 2 \\
\hline Left medial visceral rotation & & & 2 \\
\hline Relaparotomy & & 2 & \\
\hline Enteroenterostomy & & & 2 \\
\hline Trauma total & 19 & & 26 \\
\hline Amputation & & 2 & \\
\hline RLE & & & 1 \\
\hline LUE & & & 1 \\
\hline
\end{tabular}

Total $=19$ cases ( 21 including amputations)

Individual $=26$ procedures (28 including amputations)

Table 7: First exposure operations and procedures

\begin{tabular}{llll}
\hline All categories & No. & Operations & Procedures \\
\hline Burn & 112 & $46 / 112$ & \\
Trauma (21, if & $19(21)$ & $0 / 19 \geq 2 / 21$ & $6 / 26$ \\
amputations) & & & \\
Emergent general surgery & 16 & $1 / 16$ & \\
Elective general surgery & 14 & $11 / 14$ & \\
Plastics (reconstructive) & 8 & $8 / 8$ & \\
Laparoscopic bariatric & 3 & $3 / 3$ & \\
\hline All total & 172 & $67 / 172(39 \%)$ & $6 / 26(23 \%)$ \\
\hline
\end{tabular}

all these reasons. It is important to have additional fellowship experiences to gain a better understanding of the qualitative and quantitative benefit, since many of the operations and procedures performed are fundamental for trauma training, and although not performed for the first time by the subject fellow, we propose would still be largely performed for the first time for a majority of trainees. Such cases that were not first time exposure for the subject surgeon, as left and right cardiac repair, pleural repair, open pericardial window, nephrectomy, iliac vein repair, distal pancreatectomy, and visceral rotations, perhaps would be first exposure in most trauma fellows experience. 
The 20-day burn experience accomplished roughly 25 to $33 \%$ of what US burn centers with fellowships report in a year (300-500 burn cases/year). Most acute care surgery fellows complete fellowship with no burn care experience at all. Qualitatively, the subject fellow gained a level of comfort in burn surgery for severe electrical injuries and the related reconstructive cases not previously possessed prior to the international fellowship. Therefore, nontraditional experiences such as the extensive burn surgery experience, and alternative approaches to STSG, inguinal hernia repair and laparoscopic cholecystectomy, provide broadening surgical skills and perspectives for fellowship training.

If the average 5-year surgical residents trauma ACGME case log productivity is considered, rotational experience would accomplish what is the major operative trauma requirement in ten 12-hour calls. To further illustrate this point, this roughly equates to what would be just 2 months of a typical trauma rotation time in United States residency programs. Additionally, given previous operative case log reports, graduating chiefs trauma productivity as approximately 39 cases in 5 years, is achieved in just 2 months time (Figs 1 to 5 ). ${ }^{5}$

Astonishingly, in 21 days, the operative report is roughly half of the subject fellow surgeons total year's operative case load in a busy American urban level one trauma center fellowship experience (individual data and national data not officially reported). This may underestimate what most trauma fellows' potential quantitative benefit given the average trauma fellow's operative experience in the average fellowship. This experience is one that is challenging to replicate in a familiar land with a familiar people.

The rotation was a 21 days experience with 1 day free of clinical responsibilities. The subject surgeon worked greater than 12-hour days and traveled between four different hospitals. The 1 day off was spent touring the countryside of Cali, and gaining insight on the successes of a 40-year-old marriage between a surgeon mentor and his wife. Friday nights were an exhibit of personal hospitality in eating and drinking at Dr Ricardo Ferrada's residence, but also one in professional hospitality as he shared his experiences and path from some of the most devastating times in Colombian trauma surgical history to becoming Cali's expert in burn injury and surgery.

The social interactions in a foreign culture were welcoming. Almost immediately, autonomy was granted in the operating room at the university public hospital, where most of the major trauma cases were conducted. PGY-3, PGY-4 and 5 surgical residents had trauma experience that paralleled the subject fellow's experience. An acute care surgery fellow, sent to Colombia from Nicaragua, added not
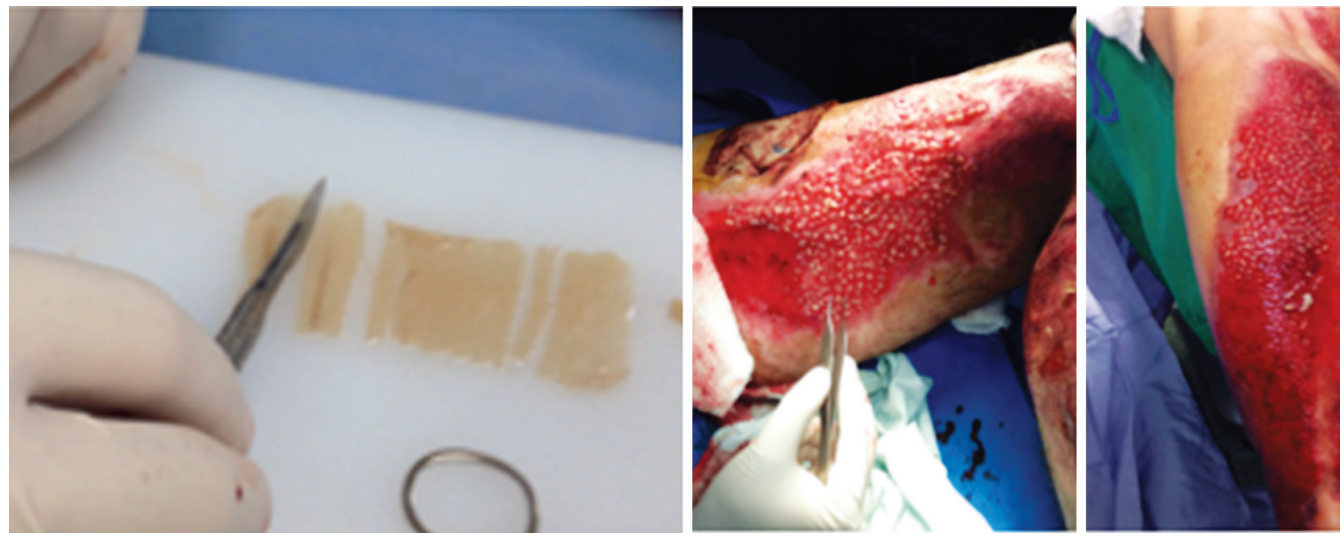

Fig. 1: Meek micrografting
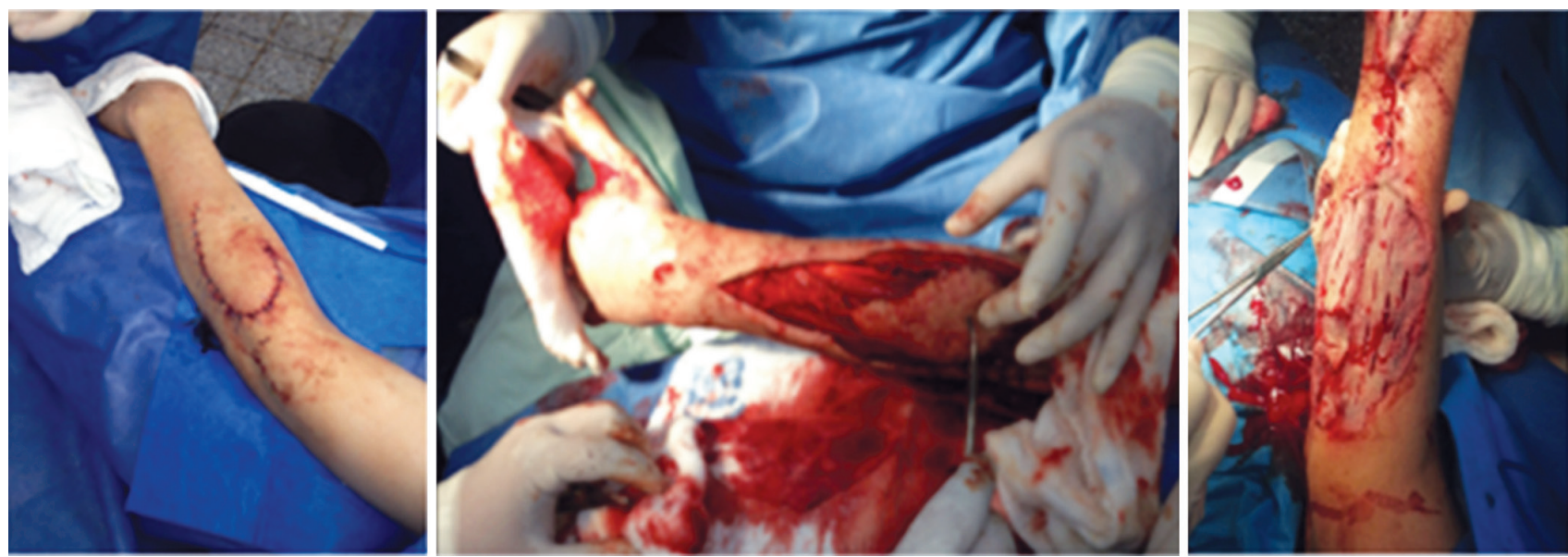

Fig. 2: Staging of ulnar island pedicle flap 


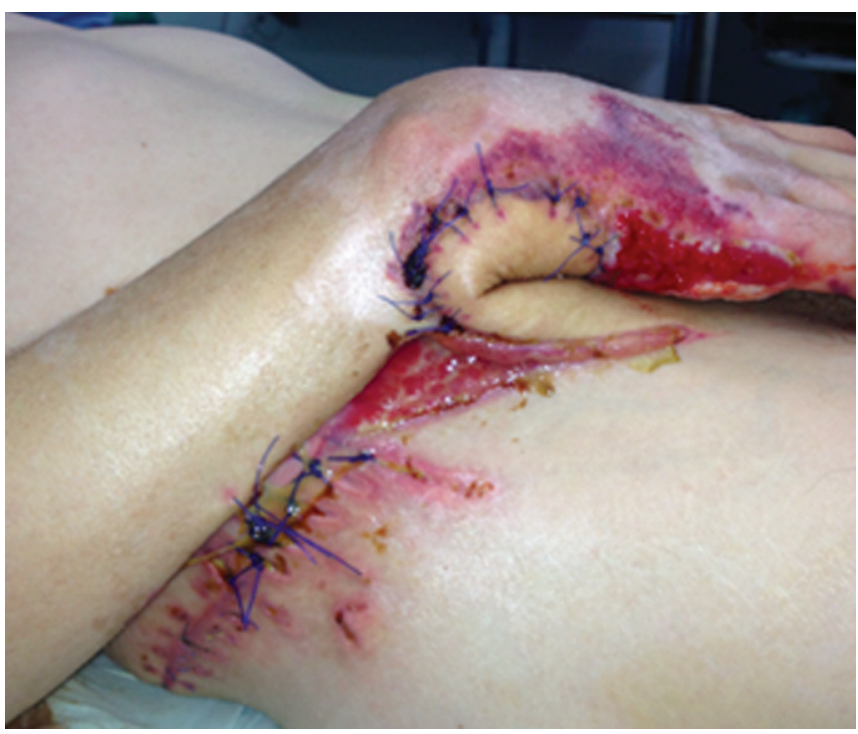

Fig. 3: Groin flap for work-related electrical hand injury only to the surgical skills being honed at work, but the honing of goals and perspective as friendship developed. The fellow spoke of leaving his wife and daughter because his community, once he became 'an expert', depended on him to return and be the sole trauma surgeon in one of the poorest regions of the world. Other professional interactions were welcoming as well. With our known effort in the United States to solidify, the acute care surgery model, the Chief of the emergency service at Universidad del Valle and Dr Carlos Ordonez discussed their similar objective. Their commitment to this paradigm was evidenced by the redesign of their Emergency areas to include ICUs, trauma resuscitative rooms and adjacent operating rooms. Yet, they still do humbly admit that historical financial challenges of an old university public hospital once responsible to combat the penetrating era, limits their ability to move forward to such exciting advances. The subject surgeon

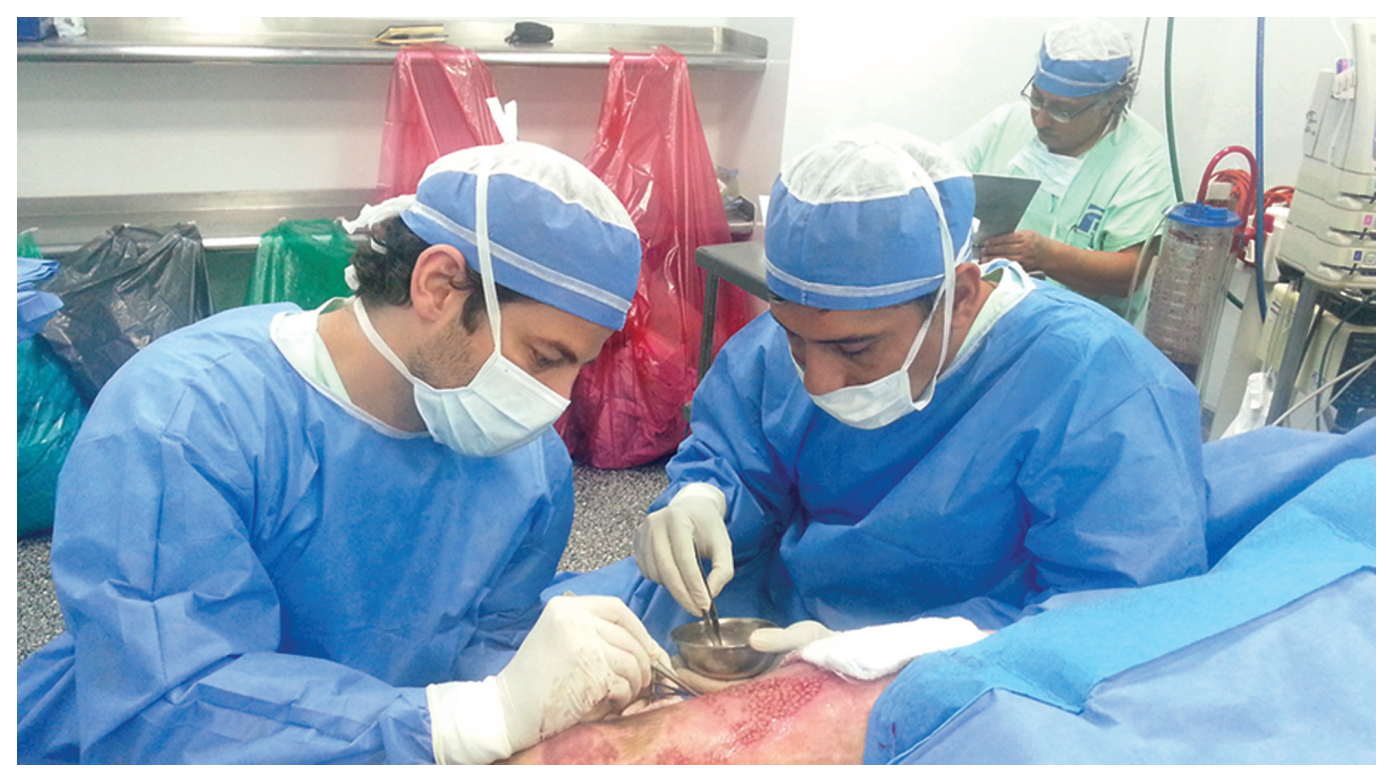

Fig. 4: Dr Ricardo Ferrada in background as Dr Peck and Dr Trochez perform Meek micrografting

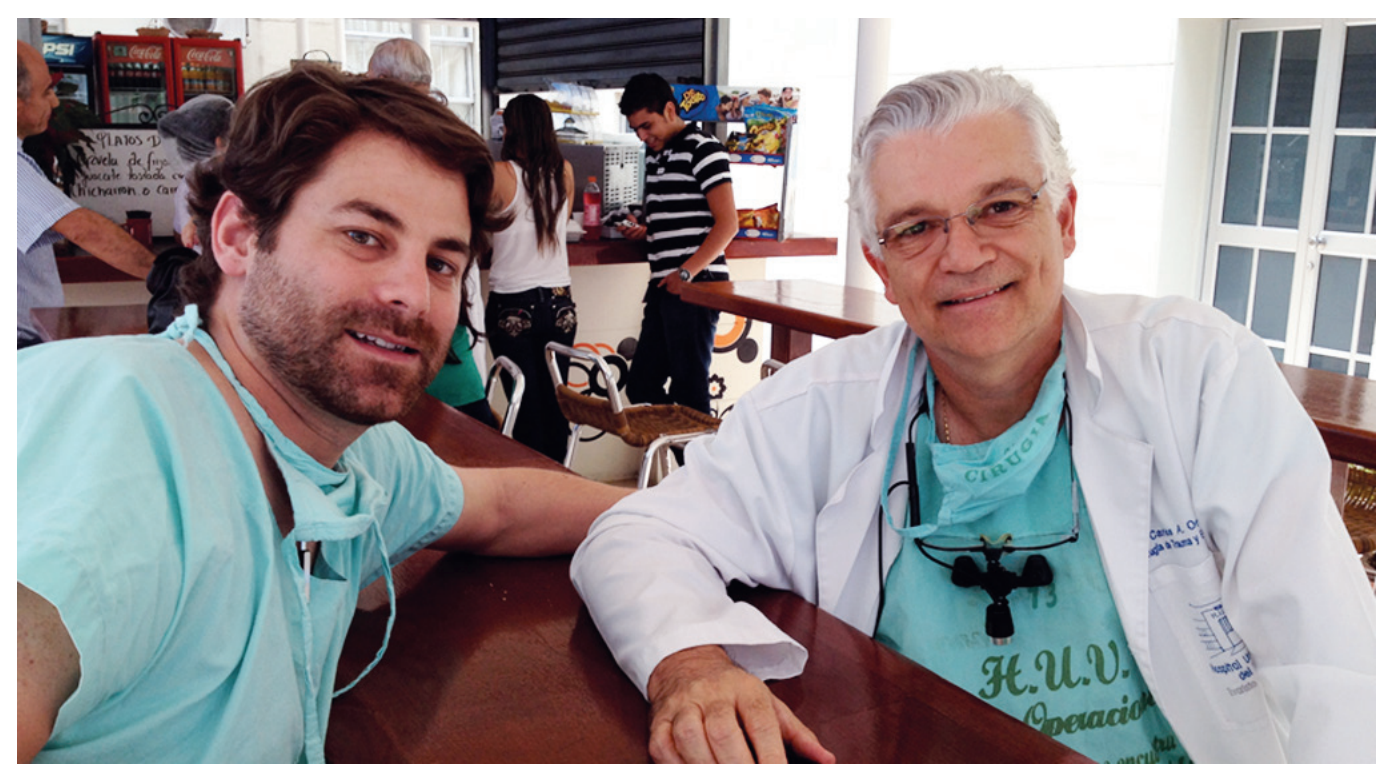

Fig. 5: Dr Ordonez and Dr Peck at the Universidad del Valle 
was entrusted with caring for a foreign country's patients and the vulnerability of sharing its obstacles to accomplishing a promising future.

There were legitimate and pragmatic concerns around an International fellowship by the home institution and host institutions. There were financial, legal and safety ramifications to be considered by both parties. Contracts, statements of goals, and partner commitments in two languages were challenging to establish. In retrospect, the subject fellow surgeon would have spent more time in the most undeserved, injury stricken areas of Colombia, but we realized predicting safety was a chief goal. Additionally, a very sobering reality check, even for the 'adventurous fellow', was purchasing a 'traveling life insurance policy' before going to Colombia. The fellow surgeon's 8-yearold daughter, posed a very sophisticated question. 'Dad, what are the kidnapping rates of American travelers?' His response, 'Do not worry, recently its much better'. The fellow surgeon asked if this was a naïve, or just an optimistic response. He also states, 'shortly thereafter, I reviewed the insurance paperwork with my wife, being sure to name her as beneficiary'. So, do realities inherently depicted here, preclude our international efforts from materializing? No, it just emphasizes that our sense of security as Americans needs to be challenged in an effort to collaborate. Yet, as we collaborate, daunting is the fact that the security of our families may invariably be challenged as well.

In order to convince himself of responsibly avoiding some risks, the subject fellow surgeon was in his mentor's company at all times. As such, his travel was unique and protected. He not once felt his personal security was in jeopardy. He asks, 'was I a sheltered American traveler'? He answered his own question, 'Perhaps I was sheltered from whatever prevents this type of travel from being a disaster. But certainly in no way, was I sheltered from the mentorship received while in Colombia.' He states, 'not only was I mentored by very accomplished technical surgeons during demanding operative cases, but perhaps greater the witnessing of lives dedicated whole-heartedly to a people, a culture, and a country. Without reservation, I was welcomed into a community, culture, family, a home and a testimony. In this, a promise exists. In our restraining world of exhausting responsibility, where inspiration thru collaboration may at times be extinguished, in the most unpredictable of forms, revitalization comes by having a purpose. What I learned during my short time in Colombia is this purpose that propels us forward, is essentially relationship.' The things that cannot be quantified by traditional means is the value of the camaraderie and friendship fostered in an almost oldfashioned master-apprenticeship, made real only in a very old fashioned relationship, one that exists only between mentor and mentee.

\section{CONCLUSION}

The Panamerican Trauma Society has established a funded fellowship experience granted through an application and scholarship, supporting this pioneering work in augmenting American fellows operative experience and training. Based on the founding work of this subject surgeon's experience, we have received additional institutional commitment to continue and further develop the international fellowship. Conversely, our international colleagues are completing fellowship rotations here at major trauma centers in the United States, and the future is promising for formal partnerships between Colombian and American trauma divisions. The future is exciting because an international network of partners to continue the fellowship experience is active and an avenue has been paved for American trained fellows to develop further expertise in trauma surgery. We report the first international trauma fellow rotation in Cali, Colombia, and demonstrate an operative experience very different than standard and current opportunities. New methods in experience and education are available for the American trauma fellow. Our experience serves as a template for future international endeavors in trauma, burn and surgical education, and demonstrates a commitment to the trauma fellow and fellowship, and the instrumental changes to come.

\section{REFERENCES}

1. Truman J, Planty M. Criminal Victimization 2011. Bur Justice Stat 2012.

2. Cothren CC, Moore EE, Hoyt DB. The US trauma surgeon's current scope of practice: can we deliver acute care surgery? J Trauma 2008 Apr;64(4):955-965.

3. Spain DA, Richardson JD, Carrillo EH, Miller FB, Wilson MA, Polk HC Jr. Should trauma surgeons do general surgery? J Trauma 2000 Mar;48(3):433-437.

4. Schuster KM, Lopez PP, Greene T, Wheeler K, Soffer D, Habib F, et al. How can trauma surgeons maintain their operative skills? J Trauma 2008 Aug;65(2):387-389.

5. Drake FT, Van Eaton EG, Huntington CR, Jurkovich GJ, Aarabi S, Gow KW. ACGME case logs: Surgery resident experience in operative trauma for two decades. J Trauma Acute Care Surg 2012 Dec;73(6):1500-1506.

6. Mattar SG, Alseidi AA, Jones DB, Jeyarajah DR, Swanstrom LL, Aye RW, et al. General surgery residency inadequately prepares trainees for fellowship: results of a survey of fellowship program directors. Ann Surg 2013 Sep;258(3):440-449.

7. Kelly E, Rogers SO Jr. Graduate medical education in trauma/ critical care and acute care surgery: defining goals for a new workforce. Surg Clin North Am 2012 Aug;92(4):1055-1064.

8. Hoyt DB, Kim HD, Barrios C. Acute care surgery: a new training and practice model in the United States. World J Surg 2008 Aug;32(8):1630-1635.

9. Chiu WC, Scalea TM, Rotondo MF. Summary report on current clinical trauma care fellowship training programs. J Trauma 2005 Mar;58(3):605-613.

10. Spain DA, Miller FB. Education and training of the future trauma surgeon in acute care surgery: trauma, critical care and emergency surgery. Am J Surg 2005 Aug;190(2):212-217. 